\title{
Assessing the Effects of Fuel Based Lighting: The Case of Kerosene Use and Disasters in Nigeria
}

\author{
E. C. Merem ${ }^{1, *}$, Y. Twumasi ${ }^{2}$, J. Wesley ${ }^{1}$, P. Isokpehi ${ }^{1}$, S. Fageir ${ }^{1}$, M. Crisler ${ }^{1}$, \\ C. Romorno ${ }^{1}$, A. Hines ${ }^{3}$, G. S. Ochai ${ }^{4}$, S. Leggett ${ }^{4}$, E. Nwagboso ${ }^{5}$ \\ ${ }^{1}$ Department of Urban and Regional Planning, Jackson State University, Jackson, MS, USA \\ ${ }^{2}$ Department of Urban Forestry and Natural Resources, Southern University, Baton Rouge, LA, USA \\ ${ }^{3}$ Department of Public Policy and Administration, Jackson State University, Jackson, MS, USA \\ ${ }^{4}$ Department of Health Policy and Administration, Jackson State University, Jackson, MS, USA \\ ${ }^{5}$ Department of Political Science, Jackson State University, Jackson, MS, USA
}

\begin{abstract}
Fuel based lighting made up of kerosene continues to find essential use in West Africa. In Nigeria where tens of millions regularly use kerosene, adverse environmental health effects remain widespread much of the time given the mixed results. These include rising mortality and morbidity often associated with fire hazards from kerosene explosions, destruction of properties, burns, compromised vision, indoor air pollution, asthma and the disproportionate exposure of infants and women to the risks of recurrent kerosene hazards. With hospital emergency cases involving complications from kerosene hazards on the rise, adulterated products in the face of loose regulations and mass poverty has surged over the years. In all these, very little research exists to assess the risks from fuel lighting incidents and their impacts from a mix scale perspective using GIS. Accordingly, this paper analyzes the growing risks from kerosene disasters in Nigeria. Emphasis is on the issues, the trends, factors and impacts using mix scale techniques of GIS and descriptive statistics to map and track the trends spatially. Preliminary results using descriptive statistics reveal kerosene hazards in the form of fatalities through household explosions as well as health and environmental risks. Just as impact analysis identified pollution threats, the GIS mapping pinpointed the spatial dispersion of the risks and elements associated with kerosene hazards. With all these attributed to several elements from ineffective policy to economic conditions, the paper offered several remedies consisting of the need for education and enlightenment campaign, coupled with improved emergency response to fire hazards and the strengthening of policy. In highlighting the extent of kerosene hazards in the country, there is opportunity for resource managers and decision-making to build from it and design proactive measures to mitigate future disasters for the safety of citizens.
\end{abstract}

Keywords Kerosene, Disasters, Assessment, GIS, Nigeria, Risks, Emergency, Fatalities, Wounds, Fire

\section{Introduction}

According to the literature, the production of petrol pass through many stages of fractioning procedure, starting from primary crude to numerous derivatives, part of which is kerosene, an extremely hazardous product [1-3]. Nigeria, an OPEC member, ranks high among the world's major producers of petroleum with a teeming population of almost 200 million out of which 120 million of them rely on kerosene fuel to substitute for defective electric power source for hurricane lantern lighting and stoves for cooking $[1,2]$. As a result, government statistics in the country shows the consumption of around 9-11 million liters of kerosene on a daily basis with much of that destined to the rural populace at the margins and the middle class [4].

* Corresponding author:

edmund.c.merem@jsums.edu (E.C. Merem)

Published online at http://journal.sapub.org/phr

Copyright (C 2018 Scientific \& Academic Publishing. All Rights Reserved
Aside from the volatile nature of its operation, fuel based lighting made up of kerosene continues to find essential use in the last several years in Nigeria. With millions of Nigerians known to use kerosene for domestic lighting up of their homes and cooking, adverse environmental health effects from the usage remain widespread across the country [5]. Considering that such level of consumption of paraffin products brings mixed results most of the time with mounting hazards. Cases of burns from fire accidents occur regularly in a country where fuel based lighting has deep appeal among users for domestic purposes [6]. With the news of exploding kerosene lamps and stoves and pipelines chiefly common in Nigeria [7], subsidies have kept petrol costs including kerosene much lower than in the country than other Sub Saharan African (SSA) nations in the midst of the disasters over the years. Essentially, fuel subsidy not only accounts for $30 \%$ of government expenditure in Nigeria, it gulps about 2.2-4\% of the GDP. Notwithstanding the mixed outcomes, in 2012 the country spent $\$ 8-10$ billion dollars on fuel subsidy which surpassed the $\$ 2$ billion 
earmarked for education [8-16]. For such policy ambiguities, public concerns over the high propensity to tragic endings in kerosene use in the country has now grown far bigger than ever $[17,18]$.

With many Nigerians known to regularly use kerosene for domestic lighting, industrial use of kerosene products [19], and the daily distribution to the different geopolitical zones has risen over time with bulk of that said to be in the south-south and southwest where usage stood at 10.17-6.7 million liters in 2015 [20]. In the process, negative environmental health effects from the different uses remain widespread $[6,21]$. Because the literature on kerosene disasters over the years in the country point to deep recurrence across cities, states and regions, the dominant themes cover burns, fatality, mortality, childhood accidental poisoning, adulterated kerosene, explosions involving kerosene lanterns and stoves, vulnerability of women, spills and others [22-24, 1, 5, 25-28]. The major cases that stand out stems from the 2001explosion that burned 125 victims who sought treatment at the Lagos State University Teaching Hospital coupled with the other 2,500 deemed wounded and the hundreds of deaths in Edo in $2012[1,15]$. While the havocs are reminiscent of petrol fire bomb explosions, the impacts often leave in their wake extensive wounds to the face, chest, and the abdomen of victims $[6,1$, 29]. The issues are compounded by the repeated cases of adulteration of kerosene products by some unscrupulous elements due to loose regulatory standards, poor risk prevention measures and unpreparedness of the nation's emergency management agencies in dealing with disaster outbreaks [30].

Considering that the problems do not operate in a vacuum and the fact that kerosene products are easy to be obtain, suggestions have been made about the removal of subsidy. With the problems attributed to socio-economic elements of policy and poverty and illegal refining of fuel products, very little exists in the literature to analyze fuel lighting incidents and their impacts on the environment in Nigeria from a mix scale perspective using GIS. Aside from few research efforts involving the applications of GIS into related studies, there exists a body research by Merem over the years that focused on the use of GIS as a decision support tool in environmental analysis that are germane to the current concerns about kerosene hazards in Nigeria. Seeing the focus on the impacts of ecological liabilities of oil and gas activities, fossil fuel emission monitoring, renewable energy trends in Nigeria and other areas [31-36]. These studies not only reaffirmed the proficiency of GIS to track the scale of natural resource use and the dispersion of the impacts, but there remains limited work on geo based analysis outlining the spatial dimensions of kerosene mishap in Nigeria. For that, this research will fill that void in the literature. The benefits of the study stems from the capability in showcasing the extent and form of kerosene hazards in the county so that managers can draw from it and device proactive measures to mitigate future disasters for the safety of the citizens.
Accordingly, this paper analyzes the growing incidents of kerosene use disasters in Nigeria. Emphasis is on the issues, the factors, impacts, and environmental analysis of the trends. In terms of methods, the paper uses mix scale techniques of GIS and descriptive statistics to map and track the trends spatially. The paper has five objectives. The first aim focuses on the use of geospatial technology to assess ecological impacts of kerosene use, while the second objective is to design a support device for decision-making. The third aim emphasizes the development of novel technique for identifying indices for kerosene safety. The fourth objective is to create a framework for efficient natural resource management using mix scale tools of descriptive statistics connected to GIS. The fifth objective seeks to analyze kerosene use, the associated disasters and factors. The paper is divided into five parts. The first section presents the introduction, while the second part describes materials and methods. Part three highlights the results with GIS mapping, factors and efforts. While the fourth section contains the discussion, part five provides the conclusion and findings of the research.

\section{Methods and Materials}

The study area Nigeria (Fig 1) stretches through an area measured at $923,769 \mathrm{Km}^{2}$ across 36 states from north to south. With a population of 187 million in 2016 [33], the nation is a major exporter of petroleum with much of the oil and gas produced in the Niger Delta region as highlighted in orange color in the map. As at 2015, it was among the top oil producers globally despite the $53 \%$ decline in earnings (Fig 1.2). In the past years (during the 2010 fiscal year), crude oil exports from the country went to different nations in the continents of Europe, Asia, Africa, Australia and America. From the yearly global transactions, the United States alone accounted for 43 percent of Nigeria's crude oil exports followed by India with 14 percent while Brazil and Spain imported 8 to 5 percent [18]. Accordingly, Nigerians utilize about 9-11 million liters of kerosene fuel daily at a huge fiscal burden on the state. With the limiting capacity of oil and gas infrastructure and the dwindling output in the refineries, the nation devotes more than $\$ 5$ billion annually for the imports and subsidy of paraffin. Considering also that kerosene is essentially aviation fuel that works by soaking a rag in it to ensure luminosity and commonly used in cities, the residue from its use that is often darkish from black soot and unburned fuel, constitutes a major health danger during domestic use [18].

In the process, news of exploding kerosene lamps and stoves are chiefly common in Nigeria, where the infusion of subsidies has kept petrol costs much lesser than in many nations of the Sub Saharan African region. The most dreadful report of contamination confirmed nationwide, reflects a case in which $14 \%$ of the victims perished in the Edo state area of Nigeria in the south-south region [15], alongside the deaths of 8 of 10 family members in a home from kerosene explosions in Edo. From the steadiness of 
these incidents, long-term studies found that in most hospital admissions, $96 \%$ of burn emergencies were due to paraffin device blasts [6]. Based on the frequency of occurrences, three multi-year reviews at Nigerian hospitals also attributed around $30 \%$ of all burn cases to kerosene fuel explosions involving stoves plus lanterns. In another study, injuries to females outnumber those to males by $3: 1$. Furthermore, gasoline contamination of kerosene has also been implicated in accidental fires associated with the use of kerosene illumination lamps and cook stoves [21].

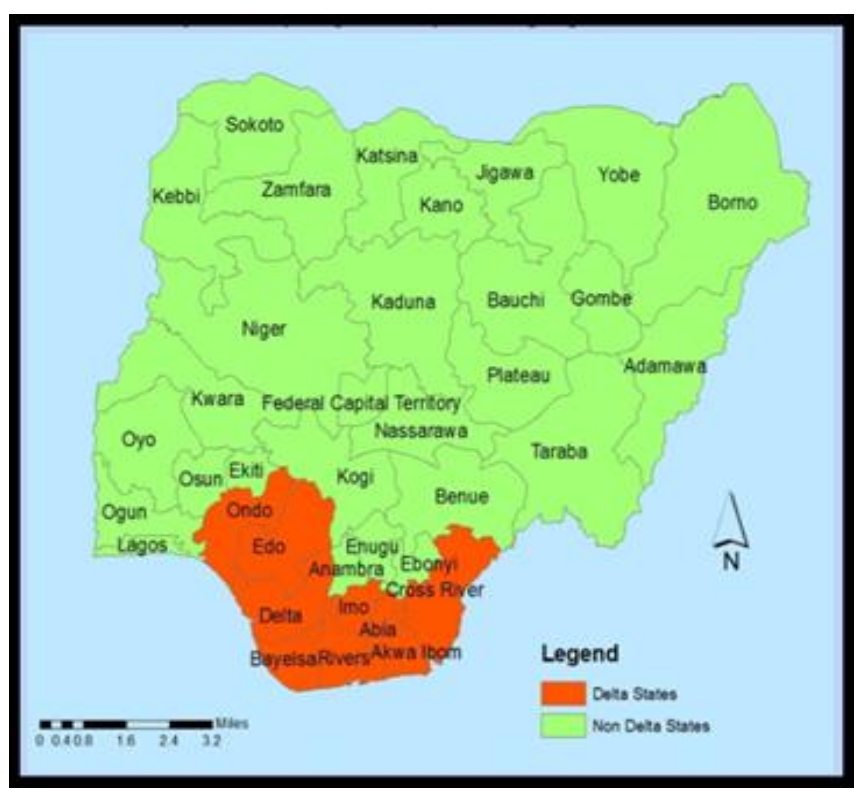

Figure 1. The Study Area of Nigeria

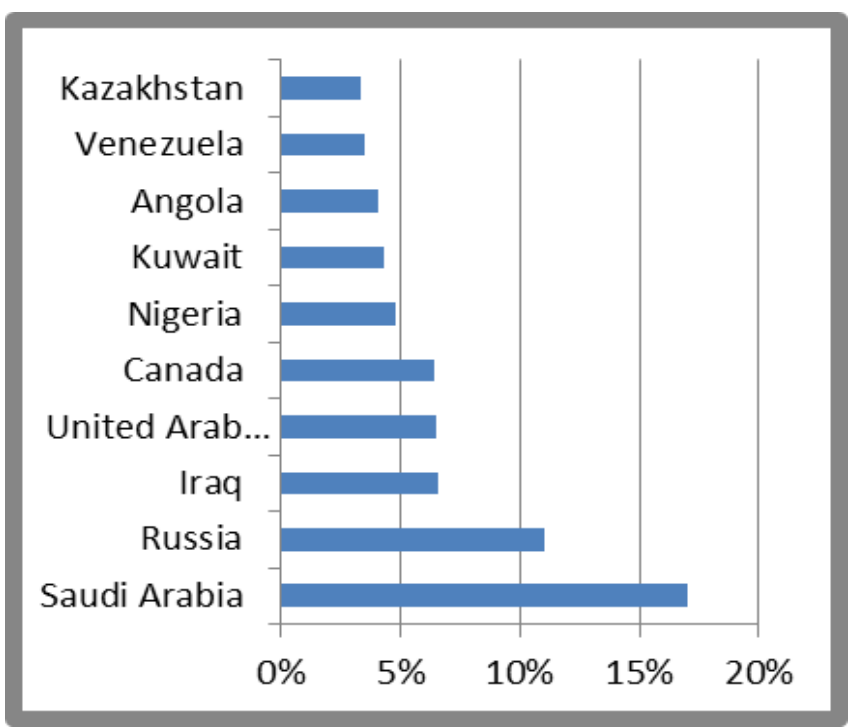

Figure 1.2. The Top Major Oil Exporters In 2015

Other great concerns in the country stem from instances of child poisoning from kerosene use across the regions over the years. In the far north, such mishaps were recurrent in the city of Kano at elevated levels during the mid1990s and late 2000s. A further look at accidental kerosene poisoning involving children across the country shows that the occurrences did extend to the other regions and states as well from the south east through the south-south and the south west. Whereas the southeast' (at Enugu and Nnewi) share of kerosene mishaps, involving children stood at sizable proportions from 2003-2012. By 2002-2011, Benin City in the south-south area of Edo state reported higher cases of kerosene poisoning as well. Notwithstanding the fact that western cities of Lagos, Ilesha, Ile Ife and Ado Ekiti were epicenters of accidental childhood kerosene poisoning over the years, the victims were mostly from the lower socio-economic stratification in society [37-40, 18]. From the emerging trends, spatial patterns, and the frequency of the hazards in the study area, opportunities are abound in the current study to undertake a risk assessment using a mix scale model targeting the affected states in Nigeria.

\subsection{Methods Used}

The paper uses a mix scale approach involving descriptive statistics and primary data connected to GIS to analyse kerosene hazards in the West African nation of Nigeria. The initial spatial information for the research was obtained from the United States Geological Surveys (USGS), the Oak Ridge National Energy Laboratory, the US Department of Energy (DOE), the US Energy Information Administration (EIA), and the International Energy Agency (IEA). With time, more data emerged from the Economic Community of West African States (ECOWAS), the OPEC annual statistics, and Euro stat, the German Agency for International Cooperation (GIZ), United Nations Statistical Division, the World Bank, the United Nations Industrial Development Organization (UNIDO) and The Nigeria National Petroleum Corporation (NNPC). While other agencies like The United States Agency for International Development (USAID) and the United Nations Economic Commission for Africa (UNECA) were also instrumental in the steps leading to data procurement. The bulk of the kerosene data for Nigeria emanated from the NNPC, Fact Fish GMbH, the UN, and the World Bank group. Aside from the total kerosene consumption information furnished through the Energy Information Administration (EIA), the NNPC and Fact Fish $\mathrm{GMbH}$, considerable portions of the kerosene disaster and hospital admission numbers, subsidy information and fuel truck accidents data for the various years came from the secondary data sources, the ECOWAS and the Nigerian National Road Safety Corps. For the purposes of analysis, the research used regional and federal geographic identifier codes of Nigeria to geo-code the information contained in the data sets. This information was processed and analysed with basic descriptive statistics, and GIS with particular attention to the temporal-spatial trends at the national and regional level. The relevant procedures consist of two stages outlined below. 


\subsection{Stage 1: Identification of Variables, Data Gathering and Study Design}

The first step involves the identification of variables needed to measure fuel based lighting impacts involving the growing pace of kerosene disaster trends among the various states in Nigeria across the six geopolitical zones. The variables consist of kerosene burns, percentage of victims, gender and population of victims, kerosene poisoning, poisoning occurrence rates, mortality, number of cases, total paediatric admission from kerosene poisoning and the $\$$ amount of kerosene expenditure. The other variables comprises of kerosene subsidies, kerosene spills, fuel tanker accidents, fatalities from fuel tanker accidents, frequency of accidental poisoning, number discharged, percentage of kerosene poisoning, and the volume of monthly kerosene consumption. Additional variables cover the volume of kerosene import, percentage of kerosene import, kerosene, consumption volume by other consumers, and the percentage, kerosene consumption by households and other consumers and the percentage, kerosene consumption by households and the percentage, adulterated kerosene burns, flame burn disasters from appliance explosion, the residence of victims, and the percentage. Additionally, access to databases that are available within the Federal and state archives in Nigeria, the ECOWAS and other international agencies and secondary sources quickened the search process. The process continued with the design of data matrices for socio-economic, energy and environmental variables covering the periods from 1995, 2003, 2010, 2011, 2102, 2013, 2014 and 2015. The design of spatial data for the GIS analysis required the delineation of state, national and regional boundary lines. With boundary lines unchanged, a common geographic identifier code was assigned to each of the units to ensure analytical coherency.

\subsection{Stage 2: Step 2: Data Analysis and GIS Mapping}

In the second stage, descriptive statistics and spatial analysis were employed to transform the original socio-economic and energy data into relative measures (percentages/ratios). This process generated the parameters for measuring the disasters, kerosene poisoning, percentage of victims, consumption patterns and volumes and rates, poisoning occurrence rates, mortality, usage levels and the trends associated with the $\$$ amount of kerosene expenditure. This was facilitated by measurements and comparisons of the trends over time. While this approach helps track the levels of use or consumption, the tables highlight volumes of kerosene import, percentage of kerosene import, kerosene spills, fuel tanker accidents and fatalities from fuel accidents.

The remaining steps involve spatial analysis and output (maps-tables-text) covering the study period, using Arc GIS 10.4 and SPSS 20.0 The spatial units of analysis consist of states, regions, cities and the boundary and locations where usage of fuel types like kerosene and the associated impacts are active. The geographic data for the West Africa state of Nigeria covered its boundaries nationwide and states, also includes ecological data of land cover files, and paper and digital maps from 2003-2013. The outputs of the data were mapped and compared, to see the dispersions of the trends in kerosene use and the factors causing the disasters in the study area over the years.

\section{The Results}

This section of the paper presents the results of the data and environmental analysis of kerosene use and disasters in the study area. There is an initial focus on the temporal profile of kerosene use and distribution, and the percentage levels, the regional assessment of hazards and the impacts. This is followed by the GIS mappings of the trends over the years. The others include identification of factors linked with the problems most notably subsidy, fuel tanker accidents and ineffective policy as well as the present efforts in the country.

\subsection{Kerosene Use and Distribution}

The kerosene use levels in Nigerian falls under three major categories distinguished by consumption among households, households and other consumers coupled with the imports and regional distribution. In the first category of users, note that of the total of 8,411 thousand metric tons (TMT) used among households in the country all through 2003 to 2013, Nigerians averaged about 724 TMT during that period. With time in the early years, the country's use of paraffin went from 1,116-1,128 TMT and 944 TMT in 2003-2005. Close to that are kerosene consumption levels in the over 700 metric ton level nationwide in 2006, 2008, and 2011. Over time, paraffin usage dropped from 573-543 TMT and 414, 478-484 TMT all through 2007 to 2013 at levels lower than the first three years. The consumption levels based on the table continued further at 944 TMT. Judging from the initial temporal snapshot, the emerging patterns show that kerosene consumption appears to have fluctuated in the country among households with the highest levels evident in the early years of 2003 through 2005 (Table 1) during the ten-year period that ended in 2013.

Among the other categories, at a total of 10,473 TMT between 2003-2013, kerosene use among Nigerian households and other consumers stayed the same (1,116-944 TMT in the first two years) but only to pick up more steam from 2005-2008 at an average of 1,600 TMT followed by a drop of about 858 TMT. In the ensuing years, of 2010 to 2013, the combined usage of kerosene with other consumers at an average value of 2,287 TMT for the year, jumped to all-time highs of 2,095-2,090 TMT and 2,492-2,471 TMT at significant levels (Table 2). Under the third category of usage among Nigerians, the pattern of kerosene use by other consumers from 2005-2013, followed a somewhat similar pattern with higher volume of consumption in the latter years and comparatively lower usage in the early periods. 
Although the use levels in 2005-2006 stood in the mid to high hundreds of TMTs, by 2007 through the other years, the numbers moved to 1,009 TMT in 2007 only to slide in 2008-2009 at 782-279 TMT. During the later fiscal years of 2010-2013, the country saw an unprecedented surge among other consumers measured at 1,544-1,988 TMT (Table 3).

In terms of kerosene import from the US, it is ironic that the Nigeria ranks high among the top 10 producing nations of hydrocarbons but still imports paraffin products from other countries like the US [41, 42]. Of great importance is the overall volume of 1,986,507 liters of imported kerosene at an average of 203,787 TMT. From the growing volumes of local demands, the import disparity levels between the various years remains evident. Even though kerosene import volumes for 1995 and 2009 and 2013, stayed minuscule at 1,000-4,000 tons during those years, evidentially, Nigeria brought in more paraffin in 2012 and 2014 at record volumes of 272,200-1,427,000 TMT compared to the other periods (Table 4). Added to that, of the total of 10,601,713,670 million liters in monthly distribution of kerosene across regions nationwide, the south-south petroleum-producing hub of the country consumed 10.17 million liters and the southwest followed up with 6.9 million liters. The north central, southeast, and the northeast on the other hand used up 933,300-310,330 and 358,000 million liters respectively. This is more than the other of regions (North West and FCT) where monthly consumption levels stood at 80,470-30,710 liters in 2014 (Table 5) [20].

\subsection{The Percentage Levels in Kerosene Consumption}

Consistent with the percentage distribution of kerosene usage in the country over the years, it is clear that the periods of 2003, 2014, 2005, and 2007 held on to the largest levels at double-digit points of 14.02 to 11.86 and 14.17 to 10.00 percent compared to the other periods. The closest rates in kerosene usage were evident during the fiscal years of 2006, 2011 and 2009 at percentage levels of $9 \%$ plus to $7.19 \%$. That was followed by the $5.20 \%$ to 6 percentage points plus levels representing the equivalence of household kerosene use rates in Nigeria between 2007-2010 and 2012 through 2013. With time, the reversal of patterns for kerosene use for households and consumers and other consumers emerged with the highest percentage points in double digit concentrated in the latter years from 2003-2013 and 2005-2013. For Kerosene use among individual households and consumers in the country between 2003 through 2013, despite the high single digit rates (of 9.73-9.47 and 8.86 -8.57 for 2003, 20052005,2006 and 2008), the lowest percentage points $(5.11,7.73-4,64)$ for households and consumers paled in comparison to the over $11 \%-13$ percent plus levels in consumption from 2010-2013. Whereas similar trends holds for other kerosene users at 14.74, 12.95, 19.22, 18.98 percent all through 2010, 2011, 2012 and 2013 fiscal years. The rates of kerosene import from the US at 13.69 to 71.83 percentage points during 2012 and 2014 seem to re-echo a recurrent trend in the country. This implies that apart from some slight fluctuations among household consumers, kerosene use among other categories of consumers' remains on the rise in the country (Tables 1-5).

Table 1. Kerosene Consumption By Households in Thousand Metric Tons (TMT)

\begin{tabular}{|c|c|c|}
\hline Year & Value & The Percentage \\
\hline 2003 & 1,116 & 14.02 \\
\hline 2004 & 944 & 11.86 \\
\hline 2005 & 1,128 & 14.17 \\
\hline 2006 & 753 & 9.28 \\
\hline 2007 & 414 & 5.20 \\
\hline 2008 & 796 & 10.00 \\
\hline 2009 & 573 & 7.19 \\
\hline 2010 & 543 & 6.82 \\
\hline 2011 & 732 & 9.19 \\
\hline 2012 & 478 & 6.00 \\
\hline 2013 & 482 & 6.05 \\
\hline 2013 & 482 & 6.05 \\
\hline Total & 8,411 & 100 \\
\hline & & \\
\hline
\end{tabular}

Table 2. Kerosene, Consumption by Households and other Consumers in Thousand Metric Tons (TMT)

\begin{tabular}{|c|c|c|}
\hline Year & Value & The Percentage \\
\hline 2003 & 1,116 & 9.73 \\
\hline 2004 & 944 & 5.11 \\
\hline 2005 & 1,750 & 9.47 \\
\hline 2006 & 1,636 & 8.86 \\
\hline 2007 & 1,428 & 7.73 \\
\hline 2008 & 1,584 & 8.57 \\
\hline 2009 & 858 & 4.64 \\
\hline 2010 & 2,095 & 11.34 \\
\hline 2011 & 2,090 & 11.31 \\
\hline 2012 & 2,492 & 13.49 \\
\hline 2013 & 2,471 & 13.38 \\
\hline Total & 18,464 & 100 \\
\hline
\end{tabular}

Table 3. Kerosene, Consumption by other Consumers in Thousand Metric Tons (TMT)

\begin{tabular}{|c|c|c|}
\hline Year & Value & The Percentage \\
\hline 2005 & 622 & 5.93 \\
\hline 2006 & 879 & 8.39 \\
\hline 2007 & 1,009 & 9.63 \\
\hline 2008 & 782 & 7.46 \\
\hline 2009 & 279 & 2.66 \\
\hline 2010 & 1,544 & 14.74 \\
\hline 2011 & 1,357 & 12.95 \\
\hline 2012 & 2,013 & 19.22 \\
\hline 2013 & 1,988 & 18.98 \\
\hline Total & 10,473 & 100 \\
\hline
\end{tabular}


Table 4. Kerosene Import from the US to Nigeria

\begin{tabular}{|c|c|c|}
\hline Year & Volume & The Percentage \\
\hline 1995 & 1,000 & 0.05 \\
\hline 2008 & 4,000 & 0.28 \\
\hline 2009 & 1,000 & 0.05 \\
\hline 2012 & 272,000 & 13.69 \\
\hline 2013 & 1,040 & 0.05 \\
\hline 2014 & $1,427,000$ & 71.83 \\
\hline Total & $1,986,507$ & 100 \\
\hline
\end{tabular}

Table 5. Monthly Kerosene Consumption by Region 2015

\begin{tabular}{|c|c|c|}
\hline Regions & $\begin{array}{c}\text { Volume of } \\
\text { Consumption in } \\
\text { Million Litres }\end{array}$ & Percentage \\
\hline South- South & $10,000,000,170$ & 94.32 \\
\hline South West & $600,000,690$ & 5.65 \\
\hline North West & 80,470 & $\mathrm{ng}$ \\
\hline North Central & 933,300 & 0.008 \\
\hline South -East & 310,330 & 0.002 \\
\hline North East & 358,000 & 0.003 \\
\hline FCT & 30,710 & $\mathrm{ng}$ \\
\hline Total & $10,601,713,670$ & $\mathrm{NA}$ \\
\hline
\end{tabular}

\subsection{The Regional Assessment of Kerosene Hazards and the Impacts}

From the high level of consumption over the years, fuel light hazards have intensified throughout the country. With the incidents stretching from the south to northern regions of the country, kerosene explosions, burns, and fatalities involving females and childhood poisoning remain widespread in the states of Lagos, Edo, Rivers, Borno and Enugu in the southern and northern region of the country. With the nature of the ongoing threats from fuel light accidents in the country, Kerosene disasters from adulterated fuel between 1984-2012 grew with many fatalities spread across gender groups especially in the southern part of the country in Lagos and Edo, Rivers and Delta states in the south-south. Of the early phases of the disaster known to have occurred, Lagos had about 53 -30 people killed and injured in 1984, and by 2001 the number of those with injuries rose to 116 along with 18 fatalities. During the same year again, additional casualties from adulterated kerosene use in Lagos stood at 59 injured and 36 deaths. Elsewhere in 2004, Edo state saw thousands of $(2,500)$ cases of injuries followed by hundreds of (368) casualties overall. Additionally, the types of kerosene disasters that ended in hospitals in the cities of Lagos, Ilorin and Maiduguri (in Kwara, and Borno states) not only involved some of the extreme circumstances. The fatalities emanated from deadly cases of burns that resulted from tainted kerosene and the impacts of lantern and stove explosions.

Other instances of kerosene hazards stems from the accidental ingestion of paraffin among little children in various areas of Nigeria. The recurrent nature of the problem involves highlights of child kerosene poisoning incidents in the northern part of Nigeria over the years. For that, within the north, the city of Kano saw substantial cases that sent many children to hospital emergency wards all through 1995 to 2008. Additional look at accidental kerosene poisoning involving children in the nation shows occurrences remain far deeper than imagined in the southeast, the south-south and the southwest and the northwest. In the southeast, the cities of Enugu and Nnewi shares' of kerosene mishap involving child kerosene poisoning hovered at 20\%-67.7\% from 2003-2012. In other places outside of the east in 2002-2011, Benin City saw $60.6 \%$ of additional cases along with Maiduguri at 30\% in 2007-2011. Recurrent incidents along these lines involving kerosene burns in the Ilorin area of Kwara state encompass the ones in October of 2001. Given the critical levels from the mishap, in the span of one week, the University Teaching Hospital Ilorin admitted 65 victims out of which 12 of them died with the other 53 placed under intensive care. In the other parts of the country such as Calabar in Cross River state in the south-south region, as at the 2008 fiscal year, the trauma units stayed quite active with the influx of 59 burn patients, with time, 37 of them exhibited trauma symptoms. This involved all patients who checked in that period. While a further breakdown of the documented disasters, showed kerosene and candle related burns characterized $33.9 \%$ of all incidents. At another south-south city of Benin in Edo state, where 62 children, sought treatment for skin burns from 2002-2006, records indicate that $52 \%$ of those burns out of the accidents occurred through kerosene explosions, which left 50\% percent of the body parts scorched [18].

\subsection{The Impacts along Demographic Groups and Gender Lines}

From the magnitude of the kerosene disasters nationwide, the overall ratio along gender lines point to more female victims than males at hospital emergency wards. In the process, the analyses across gender lines of the victims revealed startling outliers in the ratio that showed more female victims all through 1984 to 2001 among the states. In terms of the actual distribution of ratios pertaining to victims across gender, the exposures to kerosene disasters in Lagos in 2001 reinforced that pattern in a surprising exposé. Even though during the same year, in the south-south region, the ratio of women to men who experienced skin burns from kerosene disasters leveled in Port Harcourt, River state and in Edo state. In the following year, the proportion of causalities jumped significantly in 2012 in both Edo and Delta states in the south-south. In the Middle Belt area of Ilorin in 2001, the group of people classified as 18-45 years among the victims' stood out as the core bulk of those scotched, their painful ordeal came from the severe burns they sustained in a way not different from similar occurrences in Lagos. The breakdown at Ilorin across gender in the same year showed more females at $40(61.5 \%)$ than the males who were outnumbered by 25 (38.5\%) with many of 
the victims drawn from over half a dozen communities in the Ilorin area of Kwara state. In 2008 at Calabar, out of the 19 reported incidents caused by explosions, the gender ratio stood at 3:1 between women and men while the city of Oshogbo in Osun state also recorded a ratio of 1.2-2:1 along gender lines under the age groups of 1-46 years of which blaze constituted the collective cause of wounds.

\subsection{GIS Mapping and Spatial Analysis}

The genesis of spatial dimensions of kerosene disasters in the country over the years begins with the widespread network of pipeline delivery systems necessary in the movement of crude petroleum and kerosene products spread across the various geographic zones in the country. From an overall distribution map covering refineries, pipeline, distribution depots and pump stations in the country. They extend from a vast tapestry of refineries and crude oil pipelines in the lower south represented in green and dark red in the Warri and Port Harcourt areas in Delta and Rivers State in the Niger Delta onto the North Central area of Kaduna, Zaria and the Far north areas. This is followed with diversions into Kano and further down to Jos in the Middle Belt and Gombe and Maiduguri Borno state. Note also the multiple outlets in blue depicting distribution depots and the new products pipelines and products pipeline stretched onto the southeast cities of Enugu and Aba with extensions onto the middle Belt city of Makurdi in the north central area serving new distribution depots at nearby Yola. Further along the southwest and the mid-west axis near to the west of Gulf of Guinea appear more distribution networks and pump stations along Benin and Lagos serving nearby areas of Ibadan and Ore and the Niger Delta region (Figure 2).

The geographic distribution of kerosene related fire explosions highlights the hot spots in the maps where fuel disasters wreaked havoc in communities in the country. The most recent instances of these disasters occurred in the periods of 2008 through 2015 along the south western, southeastern and in the south-south zones in the southern region. Being a problem precipitated through collisions involving moving fuel tankers in densely populated areas. The incidence of fuel tanker disasters often associated with the transportation of kerosene products as shown in the map, have devastated many cities and regions since 2008-2015. Considering that, kerosene comes as byproducts of hydrocarbons and the fact that many of the refineries producing it are located in the south-south zone of the country on the lower edge of the map. It is then not surprising that fuel tanker disasters continues to be profoundly concentrated in the south with deadly explosions all through Lagos, Edo, Rivers states and Anambra states in the southern region. The spatial patterns of the trends in 2008-2010 include the incidents on the Lagos area along the Lagos -Ibadan express way and the Third Mainland Bridge. The others reflect a flurry of kerosene mishaps as evidenced with further tanker firestorm in Ovie northeast in Edo state as well as the Benin- Shagamu expressway with notable casualties between the periods of April 5 in 2013 and April 2 of 2014.
Observe also, additional incidents involving tanker explosions, which rocked the Okosia area of River State during July $12^{\text {th }}$ of 2012 . Note as well the violent flashes of recurring tanker blazes from 2009-2015 along the adjoining southeast business hub of Onitsha in Anambra state at Upper Iweka and the outskirts of the city. The ensuing inferno spilled over to moving and stationary cars and pedestrians with human casualties and property damages spread across the towns of Onitsha and Nnewi. One essential point from the emerging patterns on the map as mentioned earlier, stems from the pace at which the frequency of tanker blaze occur along both heavily populated urban areas and major high ways in the southern region compared to little occurrences in the northern zone of the country (Figure 3 ).

The central part of cases of spills involved the two cases in the north and south-south region of the country along Maikunke and Calabar axis in both Niger and Cross River state. With the damaging effect on the vegetation and soil structure in impacted areas, both areas did stand out with exposures to kerosene spill on their ecosystem from 2005 through 2012. Following that, comes the deadly explosion triggered by kerosene across the three states in the southwest and south- south. By 2008-2011, in the southwest city of Oshogbo, kerosene implosion left in its wake 37 seriously hurt people and 7 deaths with $29.2 \%$ of the tragedy attributed to burn flames. In the lower edge of the map depicting south-south zone, of the 62 victims of kerosene mishap in 2002-2006, 52\% of that involved young children. In the emerging years, in 2016, about 20 families in Borokiri area of Port Harcourt in River states also experienced kerosene disasters (Figure 4).

Additional damages from adulterated kerosene burns and explosions come from the Lagos area where many victims sought treatment in the mainland part of the city at the Lagos University teaching hospital (LUTH) in Idiaraba. In the process, from the early part of October to November of 2001, kerosene burn accidents in the area not only claimed 12 lives, but about 125 patients with burn injuries were admitted into hospital emergency at LUTH. Notwithstanding the collective anguish from such a disaster, the city endured another repeat incident that affected 94 victims in the same year. Further look on the map shows a gradual concentration of kerosene burn incidents spread across several local government areas of the state especially in the mainland area of Lagos state. With the high frequency of burn incidents firm in the central zone among the local governments, the communities of Oshodi-Isolo, Mushin and Surelere axis of the city accounted for significant levels of the mishaps (at 6\%, 29 to 34.6\%) while those impacted by kerosene burns at Ajeromi-Ifeledun zone in the south of the state stood at 14\% (Figure 5).

Other notable impacts of kerosene disasters consists of the spread of the skin burn incidents from adulterated products stretching from Ilorin in Kwara state along the middle Belt/ in north central Nigeria and Oshogbo area in Oshun state onto the cities of Benin and Calabar in the south-south zone. With multiple incidents visibly evident on the left side of the map in 2001, in Ilorin Kwara state, note the number of 
victims, the casualties and those who underwent treatment in hospitals coupled with the number of cases, the 4 affected local government areas, and the 58 victims therein. The same thing followed in the south west at Oshogbo with 36 burn victims from 2000-2004. Additional occurrences involved cases in Benin and Calabar in the south-south where 59 citizens suffered skin burns (Figure 6).

The ratio of people killed and the gender, and those injured shows a common pattern not different from the previous configurations already outlined. Of the areas at the center of these disasters involving deadly cases resulting from kerosene adulteration, four areas in the southwest and the south-south comprising of Lagos, Delta, Rivers state and Edo remain the states with most casualties and affected victims. On the left hand side of the map depicting Lagos, from 1984-2001, see that the area suffered notable mayhem in 1984 involving men and women at a ratio of 1:9 followed by $53-30 \%$ rates of injured and dead victims. From then on, the resurgence in casualties from adulterated kerosene occurred in 2001 at two different periods in the same year. Outside of the southwest region in the map, the dreaded mishap returns to the south-south zone where Benin City in Edo State saw hundreds to thousands of injured and dead persons as manifested in 2004, 2011-2012. The disasters continued unabated with minor uptick again along the lower south-south zone of Warri and Port Harcourt with the numbers ranging from 11 deaths and 11 injured during 2012 and 1-5 gender ratios again among those that sustained injuries and the causalities in 2011. Again, the south-south and the southwest seem to have dominated the causality rates more than the north and southeast regions during the periods under analysis (Figure 7).

Considering the mounting threats of food poisoning nationwide, during the period 1984 through 2012, several cities located in handful of states experienced kerosene induced food mishap involving young children. Being no respecter of geographic and political boundaries and with the manifestation of these problems clearly evidenced in the upper north, the southeast and south-south portions of the country. The pace of accidental kerosene food poisoning in the country also involves the visible display of the patterns spread across the core north where major occurrences of the incidents rattled Kano at the rates of 74.3-50\% all through 1995-2008. The number dropped to $30 \%$ further along the northeastern city of Maiduguri from 2007-2011. On the southwest portion of the map comes notable variability on the growing occurrences of paraffin intoxication in the states of Ekiti, Osun and Lagos with Ilesha Town and Metro Lagos having identical incidence rates of $14 \%-18.8 \%$. In the same region, the cities Ile Ife in Osun and Ado Ekiti posted much higher rates of accidental kerosene ingestion of $37 \%$ to $40.9 \%$ between $1988-1989$ and 2015 . Aside from the initial concentration of these problems in the other regions, with time came a gradual shift of the spatial patterns towards a group of major cities in the lower southern region of the country. Of these areas, in the southeastern region, surges in kerosene mishaps showed further presence (at Enugu and Anambra) in 2003-2012. During that period, paraffin accounted for $20 \%$ of food poisoning at Enugu, while in Nnewi, Anambra state, paraffin ingestion rates topped $67.7 \%$ of all cases associated with food poisoning. Regarding the lower south-south region, Benin City's accidental poisoning also accounted for all reported cases of kerosene disasters therein at $66 \%$. With these instances of kerosene tragedy deeply visible in the various cities, it is clearly evident that the concentration patterns of kerosene poisoning in the country transcends every region from the upper north to the lower south-south. As manifested so far, these zones also have had their own shares of exposures to childhood kerosene poisoning, as well as admission to the emergency wards of major university teaching hospitals (Figure 8).

The spatial distribution of future projects to address kerosene shortage in the country shows they are mostly in the off shore areas. The only exceptions were the two projects involving Dibi for the long-term and the Sona Field project and Grube phase 2 projects situated a bit more closer to inland along Beyelsa and Rivers States in the deep south with Agip and Chevron as the major sponsors. Further deep on the map towards the Gulf of Guinea and the Atlantic coast emerges a spectra of offshore fields spread across the western, northern, eastern, and southern portions of the Gulf of Guinea. Along the upper northern coastal zone of the Gulf note the location of three proposed fields (satellite development phase, Zabazab-Ethan) for Chevron and ENI followed by the EGMA, UGE oil project on the northeast side. Adjacent to the same vicinity further down to the south west comes a dispersal of multiple offshore fields beginning with Erha North phase 2, and the NSIKO project and another trio of ventures along Bonga north and south in the south east of the Gulf of Guinea. Overall, the GIS mapping revealed spatial dispersion of the risks, future projects and elements associated with the hazards attributed to socio-economic factors (Figure 9).

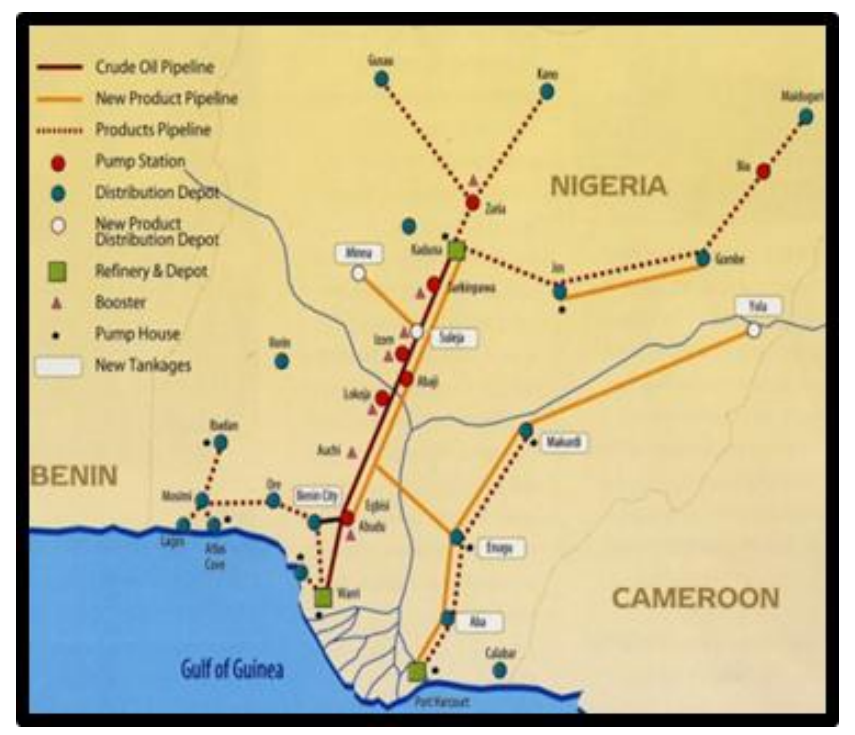

Figure 2. Crude Oil Distribution Network 


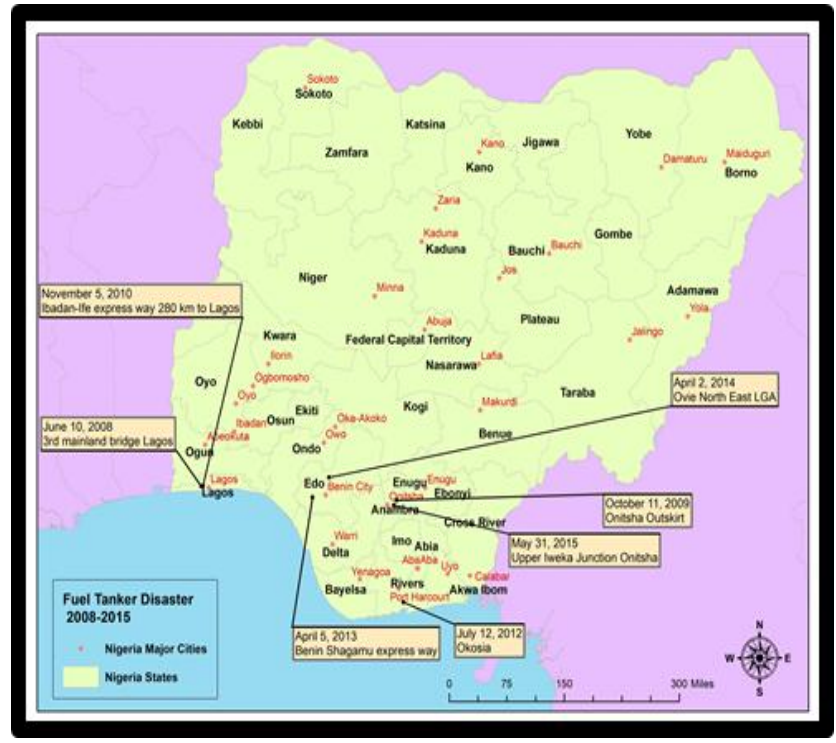

Figure 3. Fuel Tanker Explosions in 2005-2008

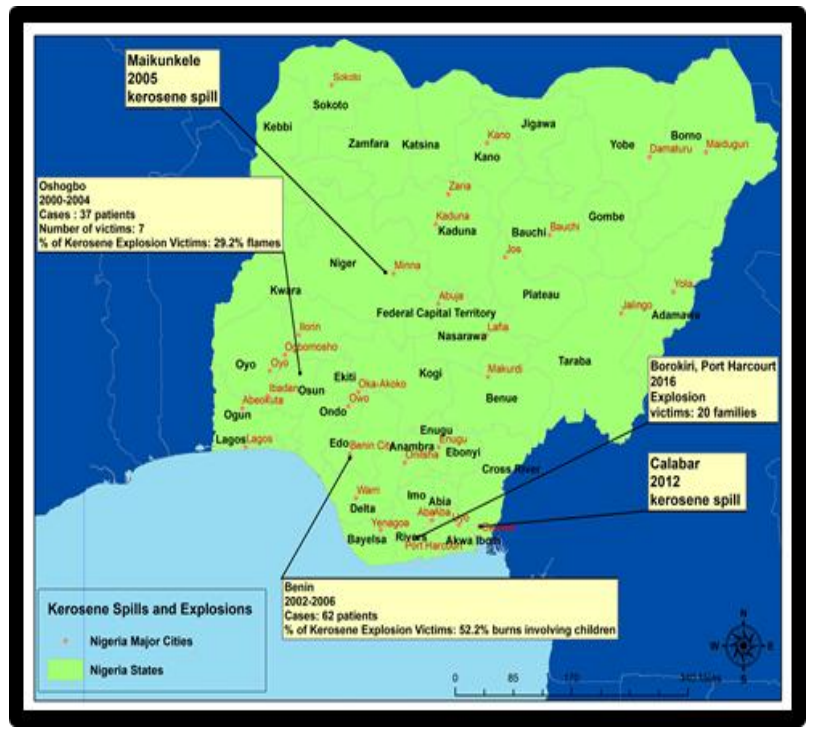

Figure 4. Kerosene Spills and Explosion in 2000-2016

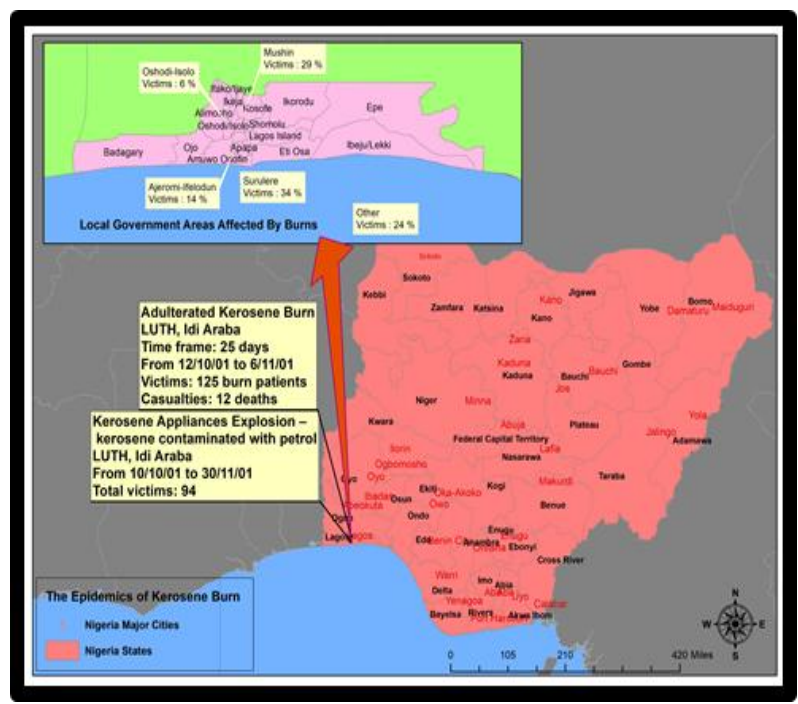

Figure 5. Adulterated Kerosene Burns 2001, In Lagos

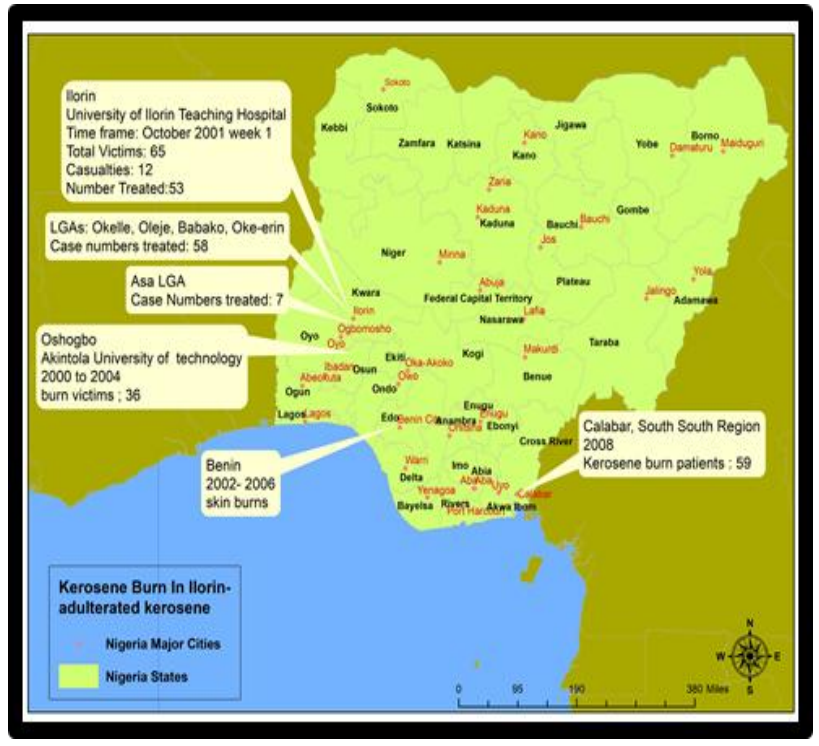

Figure 6. Burns from Adulterated Kerosene 2001, Ilorin Kwara, State

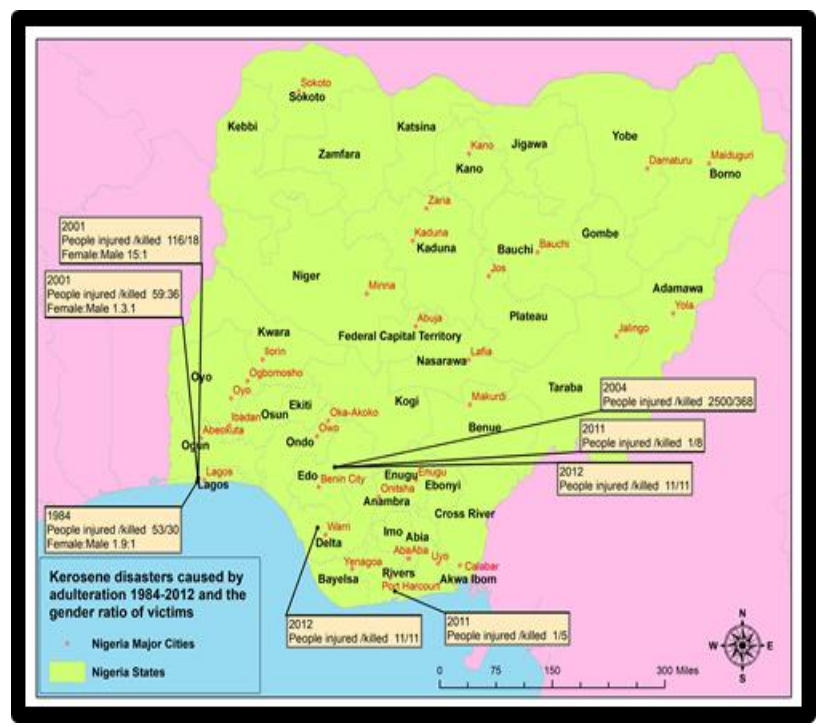

Figure 7. Gender Ratios and Victims of Kerosene Adulteration

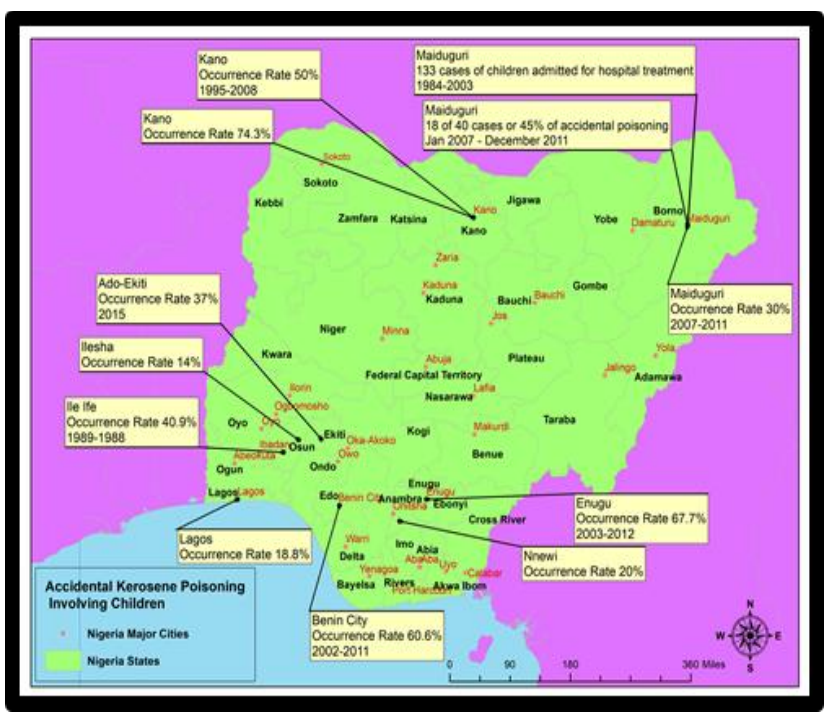

Figure 8. Accidental Kerosene Poisoning 


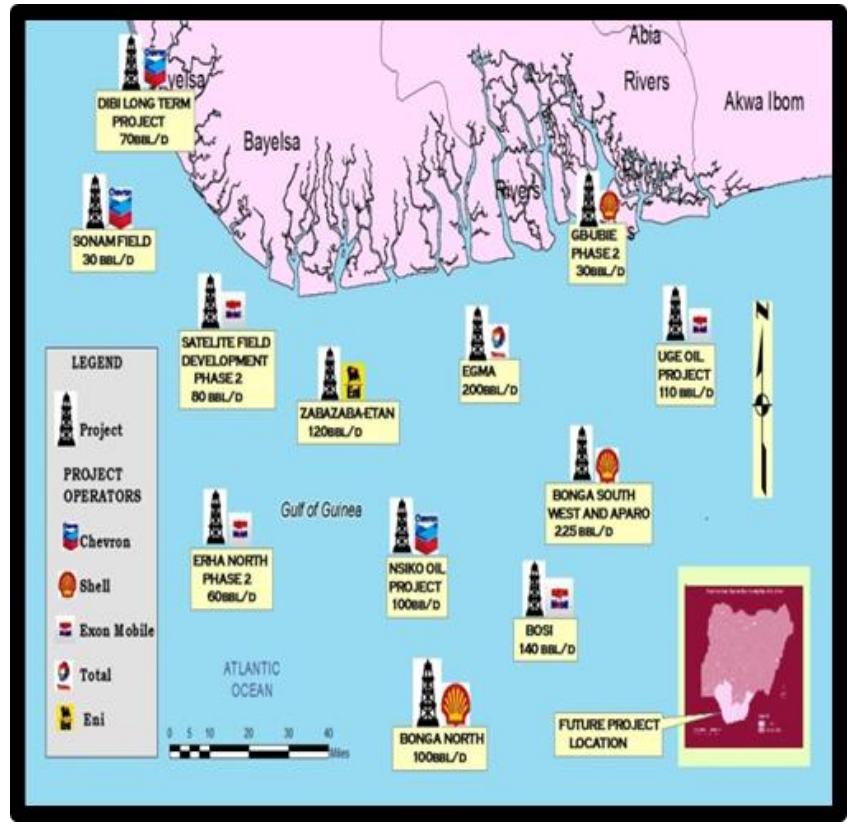

Figure 9. Map of Future Projects

\subsection{Factors Responsible for the Widespread Disasters}

In the context of factors associated with the frequency of kerosene disasters, it is clear that they do not operate in a vacuum. They partly come from a set of socio-economic and physical elements such as subsidies, fuel tanker accidents and ineffective policy. The complete examination of these elements is presented in the following paragraphs.

\subsubsection{Proliferation of Kerosene Subsidies}

Conceptually, kerosene subsidies refer to government assistance disbursed to ensure prompt delivery to needy population to balance their income and manage the supply in a way that shapes the marketing of these products. This also involves state procurements of kerosene products and the provision of a safety net for domestic users in case of eventual volatility in the market place [43, 44]. Considering the seemingly, harmful side of kerosene subsidies in the market place and the linkages to unnecessary ecological burdens on citizens. The ambiguities embedded in subsidies distort the marketing of paraffin in a way that affects the health of citizens and environmental quality in Nigeria. Subsidy opponents criticize its misuse and impact given the easy access to many poor Nigerians. In the country, excessive kerosene use and distribution patterns prompted by subsidies resulted in unintended environmental harms. Furthermore, among the Economic Community of West African States (ECOWAS) in 2002-2010, Nigeria spent more money estimated at $\$ 16.1$ billion in subsidized kerosene than the other nations in the region. While this represents an average of $\$ 1.7$ billion annually during that period respectively, within those years, the country spent over \$2-3 billion in 2007-2007 and 2010 to sustain kerosene consumption than the other periods (Figure 10). Making subsidized kerosene fuel available is not only essential for domestic usage, but it results in access to cheap paraffin's for consumers and sometimes leads to unwanted negative externalities and overuse of the products and abuse of the goodwill behind subsidy. The unregulated distribution of kerosene products through roadside hawkers, small-scale dealers in the country and others in that way helped the proliferation of adulterated products. This is partly responsible for much of the kerosene and stove appliances related accidents among ordinary Nigerians who throng hospital emergency wards as victims. More so, the widespread accidental ingestion of kerosene by children and the resultant fatalities as seen over the years come from poor home storage and the easy access to the product. To that end, in the southeastern part of the country (in Enugu), hospital sources indicate that kerosene accounts for 44 percent of all substances responsible for accidental cases of poisoning. Had it not been for the subsidies involved and the common availability, it could have been very hard to access the products so easily and many deaths would have been prevented [18].

\subsubsection{Fuel Tanker Accidents}

The widespread cases of kerosene disasters over the years across Nigeria reflect a pattern of frequent mishaps of fuel tanker explosions common at major Nigerian Highways. Between 2005-2015 in the country based on existing information, most of the accidents originated from road mishaps involving vehicular movements on major roads in highly populated urban areas of the country especially in the southern part of Nigeria. Of great importance in the past years are the incidents involving 6 cars that were razed out following a head on collision from fuel tanker explosion in the Lagos area in 2008. In the ensuing periods of 2009-2010, note also additional incidents of the recurrent fatalities encompassing 70-400 citizens in both the eastern city of Onitsha and Ibadan-Ife expressway. Being the largest among the list of causalities, the mishap also triggered the destruction of about 150 vehicles. Further, along the years then came more tanker fuel related vehicular incidents with additional victims. From the table, during the periods of July 12 of 2013 to May 31 in 2015, as indicated in the table, the nation saw more deadly fuel tanker disasters leading to the death of 121 persons alongside 75 injured individuals. The trends continued with multiple injuries $(30,2$ and 4$)$ in 2013-2014 and another 60 in the fiscal year 2015 in the cities of Benin, Ovie north and the Upper Iweka area in Onitsha Anambra state [45] (Table 6).

\subsubsection{Ineffective Policy}

The frequency and nature of kerosene disasters in Nigeria indicate that the country lacks clearly defined laws to regulate the local and interstate movements, the storage, and distribution of highly inflammable materials like paraffin [30]. Judging from the problems leading to accidental ingestion of kerosene, the explosions involving fuel tankers, lantern explosions, and deliberate adulterations of kerosene 
and the ease with which Nigerian citizens keep the products in their homes. It is clear that there are no efficient policies in place for regulating and prohibiting the dangerous practices at the center of most disasters. Since in other parts of the world it is forbidden to store huge quantities of these inflammable materials in residential areas compared to the ease with which they are done in Nigeria. The lack of restrictive labeling laws exposes citizens especially children to the risks of accidental ingestion whenever they encounter colorless liquids like kerosene at homes [46]. In the face of infective policy devoid of regular inspections of storage depots and roadworthiness of oil tankers under command and control measures to ensure safe delivery of petroleum products to consumers, innocent Nigerians end up as potential victims. In a country known for the nefarious practices of distributing kerosene in pipeline and tankers already tainted with petroleum, huge risk levels from deadly explosions does exist [30]. Also, if existing policies had authorized alternative routes and means of moving kerosene products through built up areas like rail systems and kept indiscriminate storage of kerosene and continual sale of adulterated kerosene to the minimum, the frequency of disasters and the magnitude of causalities would have been minimized, hence the role of policy in exacerbating the issue.

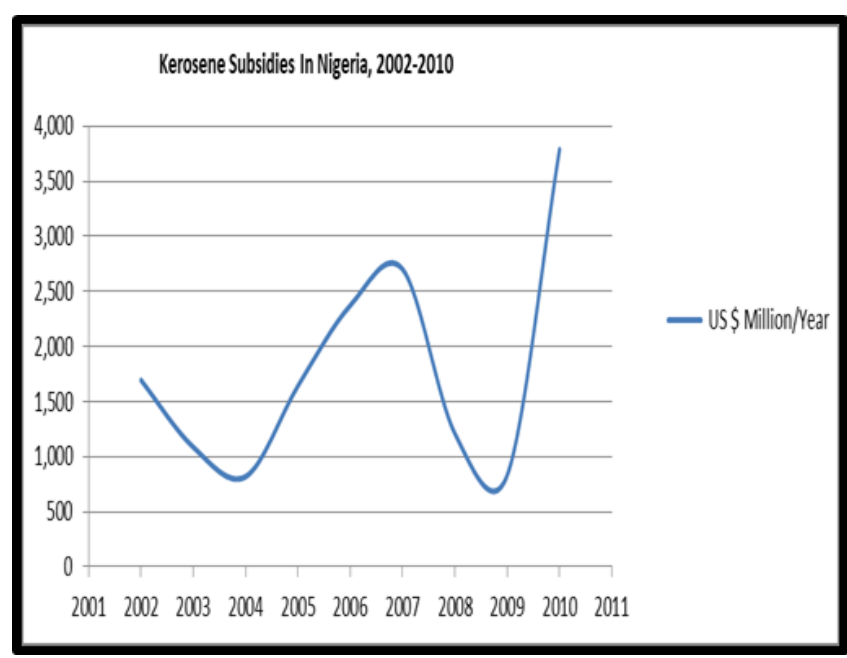

Figure 10. Kerosene Subsidies in Nigeria 2002-2010

\subsection{Evaluation of Current Efforts by Different Entities}

With the spate of problems emanating from kerosene use nationwide, government and private sectors groups are spearheading several efforts to address the recurrent nature of kerosene disasters in Nigeria. These includes the mobilization of both federal and state emergency management rescue teams, the active involvement of road safety corps, the intervention of teaching hospitals and the commissioning of future off shore infrastructural development projects to boost access to hydro carbon products including kerosene as a way to stem the tide of adulterated products and scarcities. For more on these efforts and the evaluation, see Appendix 1.
Table 6. Selected Incidents of Fuel Tanker Disaster in Nigeria 2008-2005

\begin{tabular}{|c|l|l|}
\hline Date & \multicolumn{1}{|c|}{ Incident } & \multicolumn{1}{c|}{ Location } \\
\hline $\begin{array}{c}\text { June 10 } \\
2008\end{array}$ & $\begin{array}{l}\text { About six cars were burnt in a } \\
\text { fuel tanker explosion incident } \\
\text { that took place at } 3^{\text {rd }} \text { mainland } \\
\text { bridge }\end{array}$ & $\begin{array}{l}\text { at } 3^{\text {rd }} \text { mainland } \\
\text { bridge Lagos }\end{array}$ \\
\hline $\begin{array}{c}\text { October11 } \\
2009\end{array}$ & $\begin{array}{l}\text { More than } 70 \text { people died when } \\
\text { a fuel tanker exploded after } \\
\text { heating an electric pole }\end{array}$ & $\begin{array}{l}\text { Anambra state } \\
\text { (Onitsha Outskirt) }\end{array}$ \\
\hline $\begin{array}{c}\text { November } \\
5,2010\end{array}$ & $\begin{array}{l}\text { About 400 persons died and 150 } \\
\text { vehicles destroyed in a fuel } \\
\text { tanker incident }\end{array}$ & $\begin{array}{l}\text { Ibadan-Ife } \\
\text { Expressway 280 km } \\
\text { to Lagos }\end{array}$ \\
\hline $\begin{array}{c}\text { July 12, } \\
2012\end{array}$ & $\begin{array}{l}\text { About } 121 \text { persons died and 75 } \\
\text { injured in a fuel tanker incident }\end{array}$ & Okosia, River State \\
\hline $\begin{array}{c}\text { April 5, } \\
2013\end{array}$ & $\begin{array}{l}\text { About 30 person died and a } \\
\text { number of vehicles destroyed in } \\
\text { a fuel tanker incident }\end{array}$ & $\begin{array}{l}\text { Benin Shagamu } \\
\text { Expressway }\end{array}$ \\
\hline $\begin{array}{c}\text { April 2, } \\
2014\end{array}$ & $\begin{array}{l}2 \text { deaths and 4 human injuries } \\
\text { were recorded when a fuel } \\
\text { tanker hit another vehicle while } \\
\text { trying to overtake }\end{array}$ & $\begin{array}{l}\text { Ovie North East } \\
\text { LGA in Edo State }\end{array}$ \\
\hline $\begin{array}{c}\text { May 31, } \\
2015\end{array}$ & $\begin{array}{l}\text { About 60 persons died and } \\
\text { many others injured in a fuel } \\
\text { tanker incident }\end{array}$ & $\begin{array}{l}\text { at Upper Iweka } \\
\text { Anction Onitsha, }\end{array}$ \\
\hline
\end{tabular}

\section{Discussion}

Evidently, the threats posed to the health and safety of the public by the growing incidence of kerosene burns and childhood poisoning across the country over the years creates enormous challenges to the wellbeing of citizens. Accordingly, the paper provided a deeper insight on these experiences from a mix scale perspective using temporal-spatial techniques of descriptive statistics and GIS based on socio-economic, and energy data at the state and regional levels in Nigeria. With kerosene use distributed among different categories ranging from individual, households and other consumers over the years, the temporal portrait of the pattern of usage across the country points to gradual changes in kerosene consumption nationwide with higher levels evident in the opening years at an overall volume of 18,464 TMT from 2003 to 2013. During the late fiscal years of 2010-2013, the nation posted exceptional increases amongst other consumers estimated at 1,544-1,988 TMT. Considering the rising demands in paraffin products, the country imported about 1,986,507 liters of kerosene from the US. Aside from the relatively small levels in imported items in 1995, 2009 and 2013, Nigeria imported more kerosene from the US in 2012-2014 based on the growth rates of 13.69 to $71.83 \%$ than the other years. In line with the rates nationwide, kerosene use reached biggest levels in multiple fiscal years (2003-2014 and 2005-2007). In the process, paraffin consumption among other groups of consumers not only grew in Nigeria, but given the common presence of the product, it comes as no surprise that burns and fire hazards from its usage occur with higher frequency in the country. These problems emanate from policy failures, 
fuel tanker explosions and subsidies that made petrol products cheap and commonly available. In as much as millions of citizens use kerosene for domestic lighting and cooking, the negative environmental health impacts are rife all over the country. In light of these challenges, the country remains burdened by the human and health costs of exploding kerosene lamps and stoves coupled with the accidental ingestion of the product by little children nationwide.

Considering the continual pace of usage, within the various states and regions of the nation, kerosene related disasters have reached quite elevated levels extending from the Lagos to Borno located in the southwest and northeast regions. In a setting in which many Nigerians perish annually from the complications triggered by exploding lanterns, and ovens and fuel tankers incinerating both social and natural environments. The occurrence of fuel light hazards involving blasts, injuries, ingestion, and deaths of women and children stayed widespread in the states of Lagos, Edo, Rivers, Borno and Enugu in the southern and northern regions of the country. Given the extent of the threats, kerosene calamities prompted by tainted gasoline all through 1984-2012 soared in numbers with several deaths distributed along gender lines particularly in the southern states of Lagos and Edo, Rivers and Delta in the south-south. With no relief in sight, in the initial periods of the disaster in the west, Lagos saw notable casualties that culminated in 53 deaths with 30 people seriously hurt in 1984. During 2001, the number of injured persons jumped to 116 followed by 18 deaths. The inferences that could be drawn in all these from an environmental health perspective is that the huge toll on ordinary people especially young children, women and victims whose lives were cut short by the disasters amounts to monumental loss in human resources to the detriment of communities in every region of the country.

The same thing applies also to the degradation of environmental quality emanating from the recurrent health risks unleashed by adulterated kerosene products. Knowing fully well the lethal repercussions, these events impede the rudiments of social sustainability vital in various communities. The damage done to the ecosystem from the occurrence of kerosene and fuel tanker explosions along highways through the burning of vegetation and ensuing pollution sometimes results in the impairment of functional capacity of different life forms and paralysis of life and the destruction of sensitive habitats in a nation already reeling from countless hazards. The problem seems compounded by the proximity of fuel tanker routes to both built up areas and ecological vulnerable landscapes coupled with the common access to paraffin products in Nigeria.

Looking further into the recurrent incidents of accidental ingestion of kerosene among children in Nigeria, as the study indicates, the issue remains far more extensive than expected in the southeast, the south-south, the south west and northwest. The warning signs, which must be worrisome, stems from how childhood kerosene poisoning rates fluctuated at 20\%-67.7\% from 2003-2012 in the southeastern cities of Enugu and Nnewi. Elsewhere in 2002-2011, Benin City in Edo state accounted for $60.6 \%$ of other incidents alongside Maiduguri at 30\% in 2007-2011. In the fiscal year 2004, Edo state again saw significant number of injuries and fatalities from paraffin mishaps. Notable instances of kerosene burn tragedy evident in the country in October of 2001 occurred at Ilorin, Kwara state with 12 deaths and another 53 placed under hospital treatment.

While the GIS mapping reveals clusters of areas prone to the occurrence of kerosene hazards in the country, the problems emanate from various socio-economic and physical factors associated with usage. In all these, the analytical capability of mix scale tools of descriptive statistics and GIS stood out remarkably in identifying the risks from kerosene spills, burns, fuel tanker explosions and the health issues of fuel poisoning. In that light, the paper not only showed the spatial dispersion of hazards associated with the nation's paraffin consumption patterns, but widespread usage triggered indelible and visible environmental health impacts such as loss of lives, injuries, hospitalizations, contamination of the built environment and lasting damage to communities. Using GIS in that way to assess kerosene hazards and the environmental health effects on the built up areas susceptible to the risks from the mishaps of poisoning, contamination, and explosions augments our knowledge of the extent of ecosystem stress. This in turn offers a context for assessing the communities at risk from the health hazards of kerosene disasters. In the face of the numerous issues including the common access to paraffin products, subsidies, periodic scarcities and incessant tragedies and the dependence by millions of households in the country. The significance of paraffin items remains steady, given the rising pace of consumption among households and others, and the huge demands over the years from 2003-2014. Aside from the variation in kerosene and the impact on the human environment, the proficiency of GIS in pinpointing the dispersion of environmental health risks of kerosene use and the emergent disasters does stand out. Accordingly, the research not only identified kerosene import dependency on the part of Nigeria given the limited capacity of local refineries and the current efforts through new projects to boost production. It proffered solutions to remedy the issues identified with suggestions ranging from the need for education to continued use of GIS, and the strengthening of policy, and the development of a national kerosene information system. For more on the recommendations, see Appendix 2.

\section{Conclusions}

This part of the study presents the closing section of the enquiry with illuminating findings on kerosene disasters based on the following headings. a) Consumption of kerosene products on the rise nationwide; b) Growing impacts from the disasters; c) Kerosene disasters linked to many factors; d) The use of mix scale approach in the study quite effective. 
Based on the study, significant amounts of fuel-based lighting like kerosene consumed regularly by millions of Nigerian households and other segments of the economy for lighting and cooking trigger huge environmental health impacts. From 2003 through 2013, kerosene consumption went from 8,411-18,464 thousand metric tons for households and consumers along with additional 10,473 TMT for other consumers. For that, the enquiry not only showed the regional patterns of consumption of kerosene products, but also of the total of 10,601,713,670 million liters of kerosene consumed in the country in 2005 , the south-south region accounted for $94.32 \%$ of all the used products followed by the southwest region at $5.65 \%$. With time, kerosene import reached unprecedented high of 1,427,000 at $71.83 \%$ in 2014. Notwithstanding, the surge in the consumption of kerosene, there were some visible fluctuations in the imported products from the US. This sounds quite surprising considering Nigeria's position as one of the top 10 exporters of petroleum products, yet still imports kerosene from the US.

The assembling of information on kerosene use patterns in this research remains somewhat essential in the nonrenewable energy sector. In the nonrenewable area, yearly and monthly data on commodity demands nationwide are estimated frequently among traders and decision makers in Nigeria and banking centers of the world for the purposes of gauging market pulse and reactions to deficits and surpluses in the products. Accordingly, the enquiry as undertaken herein thus provides the needed tool for petroleum resource managers and those in the energy sector charged with the task of projecting the industry and securing ventures to increase income flows. Because of the current state of energy policy in the face of dysfunctional infrastructure, the falling refinery outputs, and the commitments to investments for upgrade in the nation. This study does stand out in offering a rare insight onto the nation's kerosene inventory for decision makers, the producers and traders in order to enable them gain profound understanding of fuel lighting products use and improve the much needed policy implementation for moving forward. Highlighting the nation's vast kerosene portfolio in that mode reinforces the essence of this enquiry in enhancing the decision-making capacity with prospects for the overall industry.

The other significant finding from the analysis comes from the effects of kerosene usage on the immediate environment, which underpins the common belief about the consequences of human-nature interfaces with unwanted externalities over time. The impacts of kerosene spills on the ecosystem involve two cases in both the northern and south-south regions of the country along Maikunke and Calabar in Niger and Cross River state. With the destructive impacts on vegetation and soil structure in affected sites apparent, both places saw exposures to kerosene spills with damages to their ecosystem all through 2005 to 2012. After that, come the lethal kerosene explosions that rocked three states in the southwest and south-south. In all these, from 2008-2011, in the southwest city of Oshogbo, kerosene explosion left 37 people extremely hurt with 7 deaths of which $29.2 \%$ of the tragedy were linked to burn flames. The same pattern holds in the additional instances of adulterated kerosene burns and explosions that left 125 victims in the Lagos area in 2001. Additionally, from 1984-2012, several cities experienced kerosene induced food mishap involving young children. Being a problem that transcends the upper north, the southeast and the south- south portions of the country, the occurrence of paraffin intoxication in the western states of Ekiti, Osun and Lagos showed identical occurrence rates of $14 \%-18.8 \%$ for Ilesha Town and Metro Lagos. In the same region, the cities Ile-Ife in Osun and Ado Ekiti saw much higher rates of accidental kerosene poisoning of $37 \%$ to $40.9 \%$ from $1988-1989$ and 2015 . The widespread cases of kerosene disasters over the years across Nigeria also reflect a pattern of frequent mishap of fuel tanker disasters and explosions common at major Nigerian Highways. From 2005-2015, considerable number of the accidents occurred on roads involving vehicular movements in the high-density southern urban centers. Even though kerosene, an extremely hazardous product finds ample use for domestic lighting and industrial purposes, it still constitutes major environmental health risks. With many of the dangers indicative of petrol firebomb explosions, the impacts are so extensive that they spread easily to the face, chest, and the abdomen at points of contact. Added to that, kerosene disasters lead to growing mortality and morbidity from fire explosions, destruction of properties, indoor air pollution, and the disproportionate exposure of infants and women to the risks of poisoning and burns. Just as evaluating, these hazards offer opportunity for intervention and prevention of impending incidents in the areas at risk through rehabilitation. Pinpointing these interactions of consumers and kerosene given the failure to predict their accrued effects nationwide remain a key contribution in the research for scholarship and practice. Recognizing such threats (as the environmental health costs from kerosene spills and childhood poisoning and fire explosions, burns) and other externalities as shown herein not only accords them serious attention in mitigation, but it puts future rehabilitation and interventions on affected areas across the nation on a much higher footing than ever.

The socio-economic and physical elements located within the larger petroleum sector including kerosene subsidies, fuel tanker accidents and ineffective policy are highly vital in examining the use of paraffin or fuel based lighting products and the impacts. Considering the relentless daily demand and consumption of kerosene and with the pace of local production and imports, it remains a heavily subsidized product. For that, in the ECOWAS region, in 2002-2010, Nigeria spent more money estimated at $\$ 16.1$ billion in subsidized kerosene than the others in the zone did. Making subsidized kerosene fuel available is not only essential for domestic usage, but it results in access to cheap paraffin that often leads to misuse. This created unregulated distribution of kerosene products through the hands of illegal roadside marketers, small-scale dealers and with that, adulterated kerosene accidents and fatalities from ingestions force 
victims into hospital emergencies in the country. Related to that, are also recurrent incidents of kerosene hazards involving fuel tanker disasters, explosions, and destruction of properties and human lives along main Nigerian Highways. Judging from the ease with which Nigerians keep inflammable materials in residential areas, the lack of labeling laws exposes citizens especially children to the risks of accidental ingestion when exposed to colorless liquids like kerosene at homes. Even though in all these, the nation clearly lacks efficient policies for prohibiting the dangerous practices driving most disasters. Without stringent policy requirements on rigorous inspection of loading storehouses and roadworthiness of oil tankers under command and control measures to ensure safe delivery of kerosene to consumers, innocent Nigerians remain vulnerable to the eventual disasters. In showing this, the enquiry not only re-echoed the significance of socio-economic and physical elements in the use and delivery of kerosene products, but also it indicated the manner in which the ecosystem and households could be affected by many stressors including tainted products, contamination, fire burns, explosions, spills, and other elements at the expense of the ordinary populace. Reiterating these linkages granted the exclusion in the literature adds a vital issue at the center of planning and research. Without such assessment, no one would have known how kerosene demand and production drive the negative externalities inhibiting environmental health. Given the focus on impacts, the findings helps show how countries and resource managers can respond to ecological health costs of kerosene disasters through the grouping of stressors and the calibration of fuel lighting index. These are not only vital tools aimed at sustaining policy by changing the behavior of producers, managers and the other actors; it will assist in the wise of kerosene, best practices and a better stewardship of the environment. This should make states, communities, and the federal government design effective strategies for lessening the susceptibility of the natural and built environment to kerosene hazards. Accordingly, the study provides policy makers a better grasp of unfamiliar risks factors.

From the study findings, the applications of the mix scale methodology did stand out quite convincingly in helping chart the directions of kerosene disaster research in Nigeria. Utilizing descriptive statistics and GIS mapping as operational tools under the model added new awareness to nationwide analysis of the ecological impacts of paraffin usage. Since sustainable use of fossil fuel based lighting products is critical to both production and market activities associated with the consumption in the country, the mix scale model did remain critical in standardizing or constructing the index for future appraisals. This methodology was very significant in defining the study location and in classifying the trends, as well as the compilation of data on kerosene use index and environmental health hazards matrix and the socio-economic data. The other parts of significance in the model revolves around the design of temporal and spatial distribution of kerosene consumption and the documentation of those indicators of environmental health impacted by kerosene induced hazards. It also highlighted changes in the consumption of kerosene products by households, consumers and others and the distribution of imported items and monthly use of paraffin nationwide and across the regions, inventory of fuel tanker disasters and the subsidy amount devoted to kerosene usage and others. This system remains essential for those charged with the task of carrying out geo-spatial analysis of kerosene use impacts, the assessment of fuel tanker accidents and the emergent hazards. For that, GIS mapping was highly indispensible in underlining the vast dispersion of kerosene distribution networks spread across the nation and the clusters of environmental health hazard' hotspots and the scale of their concentrations as the rudiments towards effective planning, intervention and impact assessment and rehabilitation. Pinpointing the dispersal of kerosene use mishaps and hazards in that mode aids in the enactment of much needed safety standards and stringent guidelines for the energy industry. The practical applications of a mix scale approach involving mappings and the compilation of socio-economic and physical index, as investigative tools, therefore augments our grasp of Nigeria's kerosene use trends and their benefits coupled with the environmental health hazards connected to that area of the petroleum industry.

In recognizing the extensive challenges in the kerosene component within Nigeria's energy sector, the growing usage, the economic, and households' benefits and emergent environmental health hazards in the context of this enquiry. Decision makers and academics in the nation will be pushed in the upcoming years to find thoughtful answers to several queries pertinent to the management of petroleum products like kerosene. The questions include how will the uses of kerosene products occur in an environmentally safe way? In what way will subsidy of kerosene contribute to the safety of household consumers? How will the proposals towards alternative sources of energy in Nigeria help minimize the threats from kerosene hazards in the country? Building from these set of queries, there are ample prospects for the academic community and the decision makers to refocus the debate on petroleum energy management with guidelines stressing ecologically safe use and production of kerosene. This will make Nigeria use its huge hydrocarbon bye products like kerosene more sustainably in an environmentally safe way for the mutual wellbeing of the populace and the economy and nature in the years ahead.

\section{Appendix -1}

\subsection{Evaluation of Efforts (Contd).}

\subsubsection{Readiness of Disaster Management Agencies}

Seeing that the dispatch of Federal emergency personnel to rescue and protect victims from the scenes of accidental explosions of petrochemicals, are sometimes fraught with mixed results because of the late arrivals to the scenes of 
accidents and the lack of latest high tech infrastructure needed to predict and mitigate the occurrences of most accidents smoothly in emergency management. The respective agencies at the forefront of emergency management continue to operate with meager resources under limited capacity, which do not curb the problem. For that, the mission of the National Road Safety Corp personnel remains adhoc since they are often called in only when things go wrong. Their involvement that ought to be centered on preventative measures has turned into counting the bodies of victims during damage assessment. The matter is compounded by the poor state of roads, and lack of safety standards, the overcrowded nature of built up areas where some of these accidents occur coupled with the lack of access to road safety sensor technologies to monitor and predict the volumes of traffic at remote locations that might be at risk. With no 911 telephone boot to dial from in case of fire emergency, some of the agencies are not fully equipped under current conditions to anticipate and manage kerosene disasters. Furthermore, the hospitals on their part are overstretched under difficult circumstances to respond and treat accident victims with meager resources under a neglected health care sector where annual foreign medical tests is exclusively reserved for the rich and government officials in the public service. Aside from such institutional incapacity at the expense of kerosene burn victims who flock to poorly equipped hospitals for intensive care, current emergency management response defects can still be improved upon in the country.

\subsubsection{Proposed Projects}

The problems associated with kerosene supply and unsafe use in Nigeria are quite complex that they transcend the current state of infrastructure especially limited refinery capacities and the deliberate adulteration of kerosene with petrol for quick profit. Added to that, the capacity of local refineries to meet the nation's kerosene demands has remained in doubt over the years. Given the nefarious practice of selling adulterated kerosene, and the nation's dependence on imported kerosene products from the United States and the fact that, kerosene is a hydrocarbon produced through a distillation process under different temperatures. Expanding production capacity through new infrastructure has gained attention. As a result, investors in the nation's petroleum sector are focused on stemming the tide of foregoing scarcity of kerosene with numerous projects already in place and some in the offing in the near future. All the three proposed projects from 2016 through 2017 under Chevron and shell have not only had their final decisions made about them, but they consist of onshore oil and natural gas initiatives with production capacities estimated at 70-30,000 bbl/d Along the Dibi, Gbubie and Erha north sites of the Niger Delta region. Related projects with final decisions towards commencement of operations by 2018-2019 cover the Erha north phase 2 and Bonga southwest and Aparo under construction by both consortiums of Total and Shell for deep water oil operations of $60-200,000 \mathrm{bbl} / \mathrm{d}$. The remaining groups of proposed ventures with no formal investment decision tied to their commencement time are mostly deep-water oil projects proposed by Shell, ENI, Exxon Mobile and Chevron. With these ventures slated for 2020, the production capacities range from 100,000-225,000 bbl/d (Table 7).

Table 7. Future Projects Slated For Development

\begin{tabular}{|c|c|c|c|c|c|}
\hline Project & Operator & Type & $\begin{array}{c}\text { Production } \\
\text { Capacity 000 bbl/d }\end{array}$ & $\begin{array}{c}\text { Final } \\
\text { Investment } \\
\text { decision }\end{array}$ & $\begin{array}{c}\text { Starting } \\
\text { Date }\end{array}$ \\
\hline Dibi Long -Term Project & chevron & Onshore oil & 70 & Yes & 2016 \\
\hline Sonam field & chevron & Natural gas project & 30 & Yes & 2016 \\
\hline Gbubie phase two project & shell & Natural gas project & 30 & Yes & 2017 \\
\hline Erha north phase 2 & Exxon mobile & Deep water oil & 60 & Yes & $2018+$ \\
\hline Egma & Total & Deep water oil & 200 & Yes & $2019+$ \\
\hline Bonga south west and Aparo & shell & Deep water oil & 225 & No & $2020+$ \\
\hline Bonga North & shell & Deep water oil & 100 & No & $2020+$ \\
\hline Zabazaba-Etan & Eni & Deep water oil & 120 & No & $2020+$ \\
\hline Bosi & Exxon mobile & Deep water oil & 140 & No & $2020+$ \\
\hline Satelite field Development phase 2 & Exxon mobile & Deep water oil & 80 & No & $2020+$ \\
\hline Uge & Exxon mobile & Deep water oil & 110 & No & $2020+$ \\
\hline Nsiko & Chevron & Deep water oil & 100 & No & 2020 \\
\hline
\end{tabular}




\section{Appendix - 2}

\subsection{Recommendations (Contd)}

\subsubsection{Promote Public Education on Kerosene Mishaps}

In country where many young children and women and others die annually from both the accidental ingestion of kerosene when mistaken for water coupled with kerosene burns from exploding lanterns and stoves in domestic households and fuel tanker explosions. Kerosene usage among households and the delivery mechanisms is fast becoming the path to tragedy. Since the resultant hazards pose serious impediments to public environmental health, the promotion of a comprehensive kerosene disaster preparedness education programs are reasonably essential modes to ensure public safety in the move to contain future occurrences. Accordingly, the proposed comprehensive public kerosene safety training programs provides opportunities that will keep families properly grounded in making informed decisions about the benefits and disbenefits of using, labeling and storing inflammable household products away from food items and the reach of children. Under the public enlightenment efforts, it would be imperative to periodically train emergency management workers on the most efficient ways to rescue victims by engaging the public through simulated events with their involvement in monthly evacuations drills targeting kerosene disaster at high risk communities so that citizens do not get blindsided in the event of real accidents [30]. The expectation is that this would ensure safety and reduce causalities, and panic among ordinary citizens that experience kerosene disasters on major highways and their neighborhoods. Under such settings, comprehensive educational training programs can help raise kerosene safety awareness among citizens, households, children and women so that they can have the faith to make right decisions when using the products and during evacuation and rescue missions in case of any hazards. Given the upsides, the proposed public education program could be tailor made for most neighborhoods taking into account the demographics, age group, education, and socio-economic stratification with women and children as the key targets.

\subsubsection{Strengthen Current Policy}

The countless scales of disasters occurring through the consumption of kerosene among domestic households and the transportation of the products throughout Nigeria, demands a serious response from current policy [2]. This can be done by augmenting the regulatory mechanisms with rigorous requirements on standards, built on command and control coupled with binding disclosures and reportage of disasters or impending risks by marketers, producers and transporters in the supply of kerosene to household consumers. While such actions by the state and national levels of government of Nigeria can set the pathways vital in halting the reckless use through stern punishments to those who adulterate kerosene fuel, be they roadside hawkers and underground crime syndicates. Seeing that the unregulated nature of current kerosene supply system in the country embodies an ecological time bomb waiting to explode; regulators should limit the sale of paraffin to solely authorized dealers instead of neighborhood sellers hawking on every street corner in cities across the country. The proposed policy will be useful in mitigating the ecological impacts of delivery and transportation of kerosene products and the environmental health costs involving women, children and the public in a way to rationalize policy objectives dedicated on the wellbeing of the communities and pollution prevention. Considering the vicinity of the major cities of states and regions through which kerosene fuel transportation originate coupled with the frequency of the mayhem associated with it as seen in the research. The decision makers in Nigeria should strengthen current policy through an improved and coordinated highway emergency response scheme in the face of yearly destructions in lives and properties caused by explosions involving kerosene fuel and fire outbreaks. As the new system can operate on a sophisticated digital tracking network controlling moving tankers remotely at terminals, they will be fully equipped with the capacity of directing and monitoring fuel trucks on highways and crowded areas. This will go a long way in protecting human lives in most households from the risks posed by tainted kerosene use and pollution exposure in Nigeria. Given the easy access to the products and recurrent tragedies, Nigeria may have to rethink the use of kerosene subsidy as policy instrument with recourse to alternative energy sources in future years [47].

\subsubsection{Develop National Kerosene Use Information System}

At the time of writing this paper, the bulk of data required for the study were dispersed in different organizations comprising of state, federal, international entities, multilateral institutions, and environmental NGOs. In the process, the analysis of kerosene hazards in a key OPEC oil producing country like Nigeria occurred without an integrated national kerosene information system with geospatial bearings. The development of that sort of system provides an imaginative way for addressing or tracking environmental health challenges emanating from the sector. That could attained by ensuring consistent access to information underlining the level of production, consumption volumes and the patterns of demand, the impacts, delinquent and illegal use and amount of adulterated products in circulation so as to ensure the sustainable use of paraffin for the safety of the public throughout the various regions and states in Nigeria. To augment policymaking ability and decision support mechanism, the recommended scheme would provide regular highlights of information on the locality of hot spots in the marketing and delivery of adulterated kerosene products, deficits and surplus data on kerosene. Other 
components should cover the clientele base, the number of kerosene fuel tankers in circulation and their locations, the volume of production, demands and supply and imported items, the number of disasters, causalities, and the preparedness of regulators in anticipating the risks and the impacts. In addition, the system could be strengthened further with the establishment of kerosene strategic reserves from which Nigerian will draw from during emergencies and volatilities precipitated from major disasters.

\subsubsection{Support the Continuous use of GIS}

With the result of the enquiry showing an extensive cluster of kerosene hazards spread across various regions and states in the country and the mounting environmental health risks to the citizens with fatalities and injuries involving children and women and the occurrences in the vicinity of urban centers. The assessment of kerosene disasters with the concentration of emergent impacts and the gravity visibly obvious from the recurrent pace in the tragedies at every nook and corner from the north to the southern regions of Nigeria exemplifies the effectiveness of GIS technology in displaying the spatial dispersion of the negative externalities. As a valuable decision support tool for monitoring the threats posed by kerosene externalities, GIS technologies enables researchers and decision makers to pinpoint the risks exposures in the use, consumption and production of paraffin to citizens. They not only enhance our cognizance of their scale, but they offer the basis for gauging the environmental health risks faced in communities at risk and the tools for rehabilitation. Because the human costs of the kerosene disasters through burns, fire incidents, deaths, injuries and hospital admission on built environments nationwide underlines the need for a regular mapping of the stressors and the applications of GIS as a decision support tool for mangers in Nigeria. For that, the sustainable use of fossil fuel energy products like kerosene requires also geospatial monitoring with GIS. With the externalities occurring at vulnerable communities difficult to track and predict, continual use of GIS have greater proficiency in monitoring and tracking the spatial dispersion of hazard patterns of kerosene disasters for mitigation.

\section{REFERENCES}

[1] Olugbenga, S.A. (2005). Adulterated Kerosene Burn Disaster: The Nigerian Experience. Annals of Burn and Fire Disasters. 18: $40-44$

[2] Oduwole E.O. (2013 December). Contaminated Kerosene Burns Disasters in Lagos Nigeria. Annals of Burns and Fire Disasters. 16: 4; 208-212.

[3] United Nations Environment Program (UNEP). 2014a. Light For Life Identifying and Reducing The Health and Safety of Impacts of Fuel Based Lighting. Geneva, Switzerland: UNEP, Energy branch, 1-20.
[4] Elijah. I.R. (2013). A Comparative Analysis of The Combustion Behavior of Adulterated Kerosene Fuel Samples In a Pressurized Cooking Stove. Global Journal of Research In Engineering Mechanical and Mechanics Engineering. 13:6:1.0 34-44.

[5] Ugburu A.O. (2003). The Management of An Epidemic Flame Burns Disaster Resulting From the Explosion of Kerosene Appliances Treated at The Lagos University Teaching Hospital. 1-6. Retrieved August 20 2017 From http:www.medbc.com/annals/review/vol_16/num_3/text/vol 16n3p115.asp.

[6] Mills, E. (2012). Health Impacts of Fuel Based Lighting. Berkeley, CA: UC Berkley National Laboratory, 1-25.

[7] Fadeyibi, I.O. (June 2009). Mass Burns Disasters In Abule Egba, Lagos, Nigeria From a Petroleum Pipeline Explosion. Annals of Burns and Fire Disasters. 12:2 97-103.

[8] Moyo, N. (2012 January). Removal of Subsidies in Nigeria: An Economic Necessity and Political Dilemma. Brookings Institution. Retrieved August $20^{\text {th }} 2017$ From https://www.b rookings.edu/opinions/removal-of-fuel-subsidies-in-nigeria-a n-economic-necessity-and-a-political-dilemma/.

[9] Ladislaw, S. (2016). Energy Fact and Opinion: Nigerian Gasoline Subsidy Reform. Washington, DC: Center For Strategic and International Studies (CSIS), 1-2.

[10] Ballali, S. (2012 May). What are The Socio-Economic and Environmental Impacts of Fuel Subsidy Phase Out. A Case Study of Nigeria and Venezuela. CEPMLP Annual Review CAR. 16:1-26.

[11] Akinwale, Y.O. (2013). Political Economy of Phasing Out Fuel Subsidy In Nigeria. Energy and Power. 3:4:37-43.

[12] Musa, A. (2014 December). The Impact of Fuel Subsidy Removal On Socio-Economic Development In Nigeria. International Journal of Economic and Commerce and Management. 2:12: 1-14.

[13] Ibekwe, N. (2013 March). Nigeria To Switch to Clean Cooking Gas. VOA. Retrieved August 20 2017 From https://www.voanews.com/a/nigeria-to-switch-to-use-clean-c ooking-gas/1616606.html.

[14] Eboh, M. (2016 April). Federal Government Ends Kerosene Subsidy, Pegs Price at N83 per liter. Vanguard. 1-3. Retrieved August $20^{\text {th }} 2017$ From https://www.vanguardngr.com/2016 /01/fg-ends-kerosene-subsidy-pegs-price-at-n83-per-litre/.

[15] United Nations Environment Program (UNEP 2014a). Lifting The Darkness On The Price of Light: Assessing The Effects of Fuel Subsidies In The Off-Grid Lighting Market. Geneva, Switzerland: UNEP, 1-26.

[16] Akinyemi, O. (2015). Fuel Subsidy Reform and Environmental Quality in Nigeria. International Journal of Energy Economics and Policy. 5:2: 540-549.

[17] Dikeoha, P. (2017 January). Disaster Loom As Rivers Residents Cook With Adulterated Kerosene. The Nation. 1-2.

[18] Merem, E. C. (2017, March a). Assessing the Effects of Fuel Based Lighting: the Case of Kerosene Disasters in Nigeria. In Proceedings of the 25th Annual AEHS Conference. San Diego, CA.

[19] Akujobi, C. (2015). The Impact of Kerosene Price Subsidy 
Removal On Household's Cooking Energy Consumption In Nigeria: Implications for National Development. International Journal of Managerial Studies and Research 3:5: 50-54.

[20] Business News. (2015 January). South South Highest Kerosene Consumer, NNPC. 1-3. Retrieved August $20^{\text {th }} 2017$ From http://businessnews.com.ng/2015/01/12/south-south-hi ghest-kerosene-consumer-nnpc/.

[21] Shephard, J. (2007). Kerosene Lamps and Cook stoves The Hazards of Gasoline Contamination. Pasadena, CA: Aeronautics and Mechanical Engineering, California Institute of Technology (CALTECH), 1-23.

[22] Grange, A.O. (1986). Flame Burns Disasters From Kerosene Appliance Explosions In Lagos, Nigeria. Burns 14: 2:1 47-150.

[23] Oladele, A.O. (2010 September). Burns In Nigeria: A Review. Annals of Burns Fire Disasters 30:23:3:120-127.

[24] Musa, O.I. 2002 (October-December). Epidemiological Investigation of Kerosene Burn Tragedy in Ilorin Kwara State, Nigeria. Sahel Medical Journal. 5:4:186-189.

[25] Oladele, A.O. (2016 January). Childhood Poisoning at a Tertiary Hospital In South Western Nigeria. Journal of Nepal Pediatric Society. 35:2:103-110.

[26] Ugwu, G. (2012). Childhood Poisoning in Warri, Niger Delta, Nigeria: A Ten Year Retrospective Study. African Journal of Primary Health Care Family Medicine. 4:1:321: 1-5.

[27] Nsebasi, N.O. (2012 June). Effects of Long Term Kerosene Spillage On Heterophic Micro Organisms In Soil From Niger Delta, Southern Nigeria. Journal of Applied Science Environmental Management. 16:2:195-199.

[28] Anienye, P.N. (2015 August). Assessment of the Effect of Kerosene Spill On The Physicochemical Properties of Soil Ten Years After Spill at Maikunkele, Niger State Nigeria. International Journal of Scientific and Research Publications 5:8:1-8.

[29] Lam, N. (2012 May 1-28). Kerosene: A Review of Household Uses and Their Hazards In Low and Middle -Income Countries. Journal Toxicology Environmental Health B Crti Review.15:6:396-432.

[30] Olowu, D. (2010 June). The Hyogo Framework For Action and its Implications For disaster Management and Reduction In Africa. JAMBA Journal of Disaster Risk Studies Management. 3:1:1.

[31] Merem, E. C. (2011). Environmental Accounting For Oil and Natural Gas a North American Case Study. New York, NY: Edwin Mellen Press.

[32] Merem, E. C. (2017b). Assessing Ecosystem Liabilities of Oil and Gas Activities In Southern Nigeria. Public Health Research. 7:1: 3-26.

[33] Merem, E. C. (2017c). Assessing the ecological effects of mining in West Africa: The case of Nigeria. International Journal of Mining Engineering and Mineral Processing. 6:1: $1-19$.
[34] Merem, E. C. (2010). Using GIS in Environmental Management: Green Assessment of The Impacts of Petroleum activities In The state of Texas. International Journal of Environmental Research and Public Health. 7:5: 2101-2130.

[35] Merem, E. C. (2007). GIS Applications In Global Environmental Protection: The Case of Environmental Monitoring of Fossil Fuel Emission From Oil and Gas Activities in Africa. World Resources Review. 19:3: 657-680.

[36] Merem, E. C. (2017d). Regional Assessment of Energy Trends In West Africa Using GIS. International Journal of Energy Engineering. 7:1:1-27.

[37] Adejuyigbe, E. (2002 October). Childhood Poisoning at The Obafemi Awolowo University Teaching Hospital, Ile-Ife, Nigeria. Nigerian Journal of Medicine: Journal of the National Association of Resident Doctors of Nigeria. 11:4:183-186.

[38] Fagbule, D.O. (1992 April). Kerosene Poisoning In childhood: A 6-Year Prospective Study at the University of Ilorin Teaching Hospital. West African Journal of Medicine. 11: 2: 116-121.

[39] Edelu. B.O. (2016). Accidental Childhood Poisoning In Enugu, South-East, Nigeria. Annals of Medical and Health Science Research. 6:168-171.

[40] Belownwu R.O. (2008 October-December). Seven Year Review of Accidental Kerosene Poisoning In Children at Aminu Kano Teaching Hospital. Nigerian Journal of Medicine. 17: 4: 380-382.

[41] Kohlman, M. (2014 April). Nigeria Emerging As Major Importer of US Jet Fuel, Kerosene. Washington, DC. Energy Information Administration (EIA).

[42] African Leadership Magazine. (2014). Nigeria Becomes Biggest Importer of Kerosene From The US. Retrieved August $20^{\text {th }} 2017$ From http://africanleadership.co.uk/nigeri a-becomes-biggest-importer-of-kerosene-from-us/.

[43] Ships and Ports. (2016 November). Nigeria Spent \$1billion On Kerosene Subsidy In 2015. -Osibanjo. Retrieved August $20^{\text {th }}$ Fromhttp://shipsandports.commg/Nigeria-spent-1b-ker osene-subsidy-2015-osibanjo.

[44] Ohaeri, V. (2016 July). Policy Brief: Kerosene Subsidy Reform and the Burden of Supply. Gender and Energy Policy. $1: 2: 1-4$.

[45] Okoli, C. (2015). Fuel Tanker Explosion Disaster, Road Safety and Human Security In Nigeria: A Threat Impact Analysis. Journal of Public Policy and Governance. 2:2: 68-74.

[46] Boyede, G. (2016 February). Ask The Pediatricians Kerosene Poisoning In Children -Preventable Disaster. Retrieved August $20^{\text {th }}$ From https://askthepaediatricians.com/2016/02/ kerosene-poisoning-in-children-preventable-disaster/1-5.

[47] Nwachukwu, M. (2011). Fuel subsidy in Nigeria: Fact or Fallacy. Energy 36: 2011: 2796-2801. 